Results were analysed using SPSS complex sample module version 22. Multiple regression was used to analyse the difference in prevalence of gout and utilisation of urate lowering agents.

Results: 23482 adults participants were included in the analysis. There was no further increase in the prevalence of gout in the general US population. The prevalence was $3.82 \%$ and $3.84 \%$ in NHANES 2007-2010 and 2011-2016, respectively $(\mathrm{p}=0.966)$.

Although there is a decreasing trend in the serum urate levels among patients with gout, the utilisation of urate lowering agents remained low. Only $28.2 \%$ and $29.4 \%$ of patients with gout were prescribed urate lowering agents in 2007-2010 and 2011-2014, respectively.

Among patients with gout, history of chronic kidney disease and use of thiazide diuretics are the most significant negative predictors for achieving the therapeutic target of SUV $<6 \mathrm{mg} / \mathrm{dL}$ (Odds ratio of 0.23 and 0.41 , respectively). Use of aspirin was not a significant predictor for treatment failure.

\begin{tabular}{|c|c|c|c|c|c|c|}
\hline 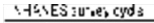 & $20: \because 0.2$ & $2 \times 0.20:$ & $30+1.012$ & 2610iviti & a) 5.200 & P,slus \\
\hline 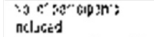 & $5 \xi^{2}$ & 8215 & sक: & 3735 & 济早 & \\
\hline 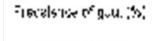 & $39.3 .4<51$ & $3 \pi[-4.1]$ & 3012.8 .6 & 4. & 3.9 .2 .4 .4 & $033 z$ \\
\hline 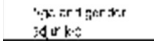 & $343: 24$ & | & $\because \div 13 \cdot \sqrt{3}$ & 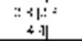 & 1 & \\
\hline
\end{tabular}

\begin{tabular}{|c|c|c|c|c|c|}
\hline & 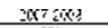 & $2003 \times 10$ & $201150 ?$ & $2 \times 132014$ & Powi: \\
\hline 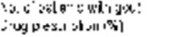 & 259 & 23 & 239 & $\{36$ & \\
\hline 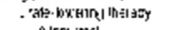 & $2^{\prime} \ell(i 1(-5+0)$ & $35819-92$ & 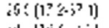 & $30 ;|243-60|$ & $x \leqslant 0$ \\
\hline s.lept. nci & 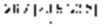 & 1 & 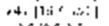 & אים & W 'lis \\
\hline 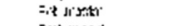 & $\therefore$ & 0 & $a c n=25$ & 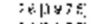 & 0.030 \\
\hline$=\infty \mathrm{n}$ r:es & 80.513 & $1.203 \%$. & $0=0.2 .1^{\circ}$ & $: 210.3 z$ & 0.179 \\
\hline 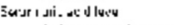 & a $72 a 0.99$ & $5.63 \pm 0 \div$ & $3.0 \pm 0.24$ & $(\varepsilon)=3 \cdot 1$ & - 060 \\
\hline 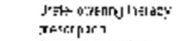 & , N\&n. & $\because 2 \pm 0$ 's &, $0.9 \pm 0 .: i$ & $6,3= \pm i$ & $\cdot .0 .1$ \\
\hline 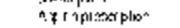 & $5 \div .06$ & :27.041 & $\$+1,0 \leq=$ & ( $\leqslant 8-142$ & ut.s \\
\hline $\begin{array}{l}\text { Thizade curclet } \\
\text { :tovil pit: }\end{array}$ & $-.10+0.28$ & $\tilde{z} .89 \pm 0.2 \mathrm{~K}$ & $367 \pm 0.58$ & $\therefore)=381$ & $0 . \ldots=6$ \\
\hline 3:1yt & 61500.22 & $5: 4: \pm 022$ & $3 \ll \pm 0 ! 4$ & S2 & $049:$ \\
\hline
\end{tabular}

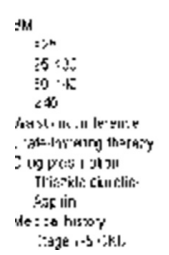

\begin{tabular}{|c|c|}
\hline 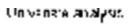 & 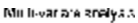 \\
\hline $1[:=x \tan t: z]$ & 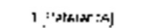 \\
\hline 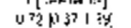 & $0=k+52)$ \\
\hline 0.48 p p.23 0.32y & $-00 k 112.5$ \\
\hline $0 A<\{0.22 .091]$ & i62|:6i-11.s \\
\hline 0.98 p..96.0 $\leqslant 9]$ & O \\
\hline $330[2.34 \cdot 4 \div 4]$ & $6 \mathrm{~m} \mid 3 / 4103:$ \\
\hline 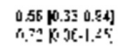 & 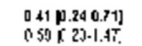 \\
\hline · & $0=3$ p.0y-0.ss] \\
\hline
\end{tabular}

Conclusions: The prevalence of gout in the US general population has not increased over the past 10 years. Although the use of urate lowering agents among patients with gout remained low, the percentage of patients with gout achieving the therapeutic target has increased over the past 10 years.

History of chronic kidney disease and use of thiazide diuretics are the most significant negative predictors for treatment success.

Disclosure of Interest: None declared

DOI: 10.1136/annrheumdis-2018-eular.5636

\section{FRI0252 TESTING FOR A CAUSAL ROLE OF MITOCHONDRIAL VARIATION IN THE DEVELOPMENT OF GOUT}

T.R. Merriman ${ }^{1}$, A. Shaukat ${ }^{1}$, A. Gosling ${ }^{1}$, M. Bixley ${ }^{1}$, N. Dalbeth ${ }^{2}$, L. Stamp ${ }^{3}$, E. Matisoo-Smith ${ }^{1}$, J. Harre Hindmarsh ${ }^{4}$, L. Joosten ${ }^{5}$, T. Jansen ${ }^{6}$, M. Janssen ${ }^{6}$, A. K. Tausche ${ }^{7}$, P. Riches ${ }^{8} .{ }^{1}$ University of Otago, Dunedin; ${ }^{2}$ University of Auckland, Auckland; ${ }^{3}$ University of Otago, Christchurch; ${ }^{4}$ Ngati Porou Hauora Charitable Trust, Te Puia Springs, New Zealand; ${ }^{5}$ Radboud University Medical Centre, Nijmegen; ${ }^{6}$ VieCuri Medical Centre, Venlo, Netherlands; ${ }^{7}$ University of Dresden, Dresden, Germany; ${ }^{8}$ University of Edinburgh, Edinburgh, UK

Background: Mitochondria execute critical roles in diverse cellular pathways. As a danger signal mitochondria induce inflammation in response to stress through NLRP3 inflammasome activation, central to gout development. We recently reported association of reduced mtDNA copy number $(\mathrm{CN})$ with prevalent gout in New Zealand Māori and Pacific (Polynesian) populations ${ }^{1}$. However the causeeffect relationship is unknown. This could be evaluated by testing for association with gout using nuclear genetic variants that associate with mtDNA CN.

Objectives: 1) Genome wide association study (GWAS) for mtDNA CN to identify nuclear and mitochondrial loci controlling mtDNA copy number 2) test any such loci for association with gout.

Methods: The mtDNA CN GWAS comprised 1340 Eastern Polynesian (EP), 816 Western Polynesian (WP) and 4579 European samples (New Zealand, Germany, The Netherlands, Scotland) genotyped on the Illumina CoreExome v24 array. 343 mitochondrial single nucleotide polymorphisms (SNPs) were evaluated. As previously described2 the median of the absolute difference in $\mathrm{X}$ and $\mathrm{Y}$ probe intensities was used as a measure of mtDNA CN, and additional 10000 randomly selected autosomal SNPs were used to calculate the principal components (PCs). A mtDNA CN GWAS was run on chromosomes 1-22 and the mitochondrial genome using Plink 1.9 .v2, adjusting for the first 10 PCs, age and sex followed by association analysis with gout adjusting by age, sex and the first $10 \mathrm{PCs}$ generated from a separate set of 3000 autosomal SNPs.

Results: The association of reduced mtDNA CN with gout in the EP and WP groups was reproduced but there was no evidence of association of mtDNA CN with gout in Europeans. Two genome-wide significant $(p<1 \times 10-7)$ variants MUC17 rs78010183 (T-allele) and SLC16A8 rs75640043 (T-allele) were associated with increased mitochondrial $\mathrm{CN}$ in EP and WP, respectively, and mitochon drial variant $r$ s3928306 was associated with mtDNA CN $\left(p=4.49 \times 10-1^{2}\right)$ in Europeans. MUC17 rs78010183 also associated with increased mtDNA CN in Europeans, with the $T$ allele also increasing $C N(\beta=0.06, p=1.07 \times 10-4)$. The $T$ allele of rs78010183 was associated with gout in Europeans (OR=9.32, $\mathrm{p}=5.53 \times 10-3)$ and the SLC16A8 $\mathrm{rs} 75640043 \mathrm{~T}$-allele was associated with gout in the WP group $(\mathrm{OR}=6.85, \mathrm{p}=5.50 \times 10-3)$. The mitochondrial variant $r s 3928306 \mathrm{~A}$ allele (very rare in Polynesian) was not associated with gout in Europeans $(\mathrm{OR}=1.09, \mathrm{p}=0.36)$.

Conclusions: That genetic variants associated with mitochondrial copy number also associate with gout provides evidence for a potential causal role of mitochondrial copy number in gout. However, the nuclear genetic variants support a causal relation of increased mtDNA CN with gout, conflicting with our previous observational report of association of reduced mtDNA CN with gout ${ }^{1}$.

\section{REFERENCES:}

[1] Gosling A, et al. Mitochondrial genetic variation and gout in Māori and Pacific people living in Aotearoa New Zealand. Ann Rheum Dis 2017 Dec 15. [Epub ahead of print].

[2] Asher FN, et al. Association of mitochondrial DNA levels with frailty and all-cause mortality. J Mol Med 2015;93:177-86.

Disclosure of Interest: None declared

DOI: 10.1136/annrheumdis-2018-eular.5017

\section{FRI0253 FOR A 5-YEAR PERIOD: INCIDENCE, PREVALENCE AND HOSPITALISATION RATES}

V. Dostanko $^{1}$, V. Yagur ${ }^{1}$, V. Apanasovich ${ }^{1}$, N. Dostanko ${ }^{1}$, A. Rekun ${ }^{2} .{ }^{1} 2-d$ Department of Internal Medicine, BSMU; ${ }^{2}$ Rheumatology Department, 9-th Minsk City Clinical Hospital, Minsk, Belarus

Background: Gout is one of the most common arthritis nowadays which has a great influence on patient's quality of life, course and outcomes of cardiovascular and renal pathology. ${ }^{1}$ Some recent papers demonstrate that the prevalence of gout has risen over the last decades and underline the scarcity or lack of epidemiologic data in different countries as well as the notable variations among them.

Objectives: We estimated incidence, prevalence and hospitalisation rates for gout in Minsk (the Republic of Belarus) for the 5 year period (2011-2015).

Methods: Minsk is a typical urban area which is considered to be representative for the urban population of the whole country. The data on the new onset gout and the first visit for gout in a corresponding year were collected from all rheumatologic services of Minsk for the 5 year period from January, 1 of 2011 to December, 31 of 2015. Only patients older than 18 years old with the diagnosis of gout according to the ICD-10 (M10) were included. The data on age and sex structure of the population of the Republic of Belarus were obtained from the annual Statistical bulletins of the National Statistical Committee of the Republic of Belarus. Hospitalisation rates were calculated on the base of statistical reports on discharges for the corresponding year.

Results: There were no significant differences in age and sex structure of the population in Belarus and Minsk for the study period. The size of the adult population, incidence and prevalence of gout, hospitalisation rates and duration of hospitalizations for gout for the corresponding years in Minsk are presented in the table 1. According to these data the gout incidence for the 5 year period changed from 25.0 (Cl 95\% 24.7-25.2) to 35.5 (Cl 95\% 35.3-35.8) per 100000 adults, the gout prevalence for the period 2011-2015 also increased from $178.9(\mathrm{Cl} 95 \% 178.3$ 179.5) to 290.3 ( $\mathrm{Cl} 95 \% 289.6-291.0)$ per 100000 adults $(p<0.001$ for both trends). There were 2688 hospitalizations in Minsk for gout for the study period. The mean age of hospitalised patients was $57.3 \pm 10.3$ years (median 58.0; range $25-87), 91.4 \%$ were men $(92 \% ; 87.8 \%-94.9 \%)$. It is worth noting that $45.6 \%$ of hospitalised patients were at the age $55-65 \%$ and $90.2 \%$ were under 70 years old with sharp decrease of hospitalizations after 65 years of age. Hospitalisation rates 